\title{
Determinants of non-participation in labour force among women of reproductive age in Nigeria
}

\author{
David Aduragbemi Okunlola ${ }^{1,2}$, Obasanjo Afolabi Bolarinwa ${ }^{2,3}$, \\ Oluwatobi Abel Alawode ${ }^{2} \&$ Olufemi Mayowa Adetutu $^{2}$
}

\author{
${ }^{1}$ Viable Knowledge Masters, Abuja, Nigeria. \\ ${ }^{2}$ Department of Demography and Social Statistics, Obafemi Awolowo University, \\ Nigeria. \\ ${ }^{3}$ School of Nursing and Public Health Medicine, Department of Public Health, \\ University of KwaZulu-Natal, South Africa. \\ Email: okunloladavid4@gmail.com
}

\begin{abstract}
Background: Studies have examined the individual-level and household predictors of women's labour force participation in Nigeria, this study went further to examine the community-level determinants of non-participation in labour force among women of reproductive age in Nigeria.

Data Source and Methods: This study analysed the 2016-2017 Nigeria Multiple indicator Cluster Survey (MICS) data of women (aged I5-49; $n=32,742$ ). Descriptive and multivariable analyses (using multilevel binary logistic regression) were performed.

Results: Results showed that $73 \%$ of the women didn't participate in the labour force. Community poverty (medium: $\mathrm{OR}=0.95$ and high: $\mathrm{OR}=1.38$ ), number of children living with a woman (medium: $\mathrm{OR}=1.05$ and high: $\mathrm{OR}=\mathrm{I} .19$ ), proportion of contraceptive non-users (high: $\mathrm{OR}=2.49$ and medium: $O R=1.59)$ and region (north: $O R=5.42)$ were significant $(P<0.05)$ determinants.

Conclusion: Hence, women (of reproductive age) in the north, in communities with high: poverty, family size and contraceptive non-use should be economically empowered.
\end{abstract}

Keywords: Labour force non-participation, women, contextual, neighbourhood, Nigeria.

\section{Introduction}

Gender gap in employment is a serious global concern. Until recently, women are tied to the traditional roles of childrearing and domestic chores. Women were not only used as a source of labour supply, working for households on the farm, but also limited to reproductive and other domestic roles. These traditional roles of women are situated in the foundation of patriarchy and the arbitrary usurpation of women in the scheme of things. However, modernisation has brought about a radical transformation in the traditional orientations and value systems that constrained women to domestic and reproductive roles. In recent times, there are expanded education and employment opportunities for women, although they still represent a disproportionate percentage of unemployment and underemployment than the general population.

Available evidence showed unemployment fluctuated between $3 \%$ and $13 \%$ between 1996 and 2000 , and from the mid-90s, it stagnated at $16 \%$ growth rate (Doreo, 20I3). Rapid population growth has been described as one of the contributing factors to high unemployment with resultant dismal socioeconomic condition and depletion of other economic gains (Asoluka \& Okezie, 20I I; Oduwole, 2015). For instance, unemployment has been identified as a key determinant of increased crime rate, incessant violence, poor health outcomes, psychological challenges among other grave consequences (Adekola et al., 2016). While high unemployment rate in the general population is associated with poor political and socio-economic situation in Nigeria, (Oduwole, 2015), it is higher among women, as well as underemployment and poorly paid jobs (Fapohunda, 20/2). Despite increased public outcry and feminists vehement advocate for bridging the gender gap in employment, women continue to be under-represented and more vulnerable to employment problems.

To address the gender gap in employment, different initiatives on women's empowerment have been introduced by international organisations and 
the Nigerian government to improve their means of livelihood and revamp the informal sector of the economy. Yet, there is no strong political will to emancipate women from the shackles of unemployment, underemployment and generalized poverty they are mired. Meanwhile, the World Bank, the principal donor agency, has funded many women's empowerment programmes in Nigeria but mismanagement and pervasive corruption have truncated its potential benefits (WorldBank, 20I4). Hence, women continue to be under-represented in gainful employment in the formal sector -owing to their maternal and domestic roles, lack of requisite employable skills, unfavourable labour laws and trading customs in the informal sector- and overrepresented in the informal sector of the economy (Gayawan \& Adebayo, 2015, Ogunlela \& Mukhtar, 2009, Lawanson, 2008). which is poorly coordinated and offers little means of livelihood in the sector (Chant \& Pedwell, 2008). This shows that Nigeria is yet to take a cue from countries that have revived their economy and tackled poverty to the barest minimum through women empowerment interventions that improved their socio-economic status.

Closely related to the high level of unemployment among women is the non-participation in labour force among women which has also raised important questions about factors that may contribute women's (voluntary) decision to not participate in labour force despite possessing the requisite working skills to work and being able to avail themselves of available and accessible economic opportunities in their locations. Also, such questions lay the platform for assessing the extent of the demand for work among women and knowing whether the fertility-related factors and socio-cultural factors (traditional and gender roles) that have been implicated as reasons for women's unemployment (Besamusca et al., 2015, Canning \& Schultz, 2012, Engelhardt \& Prskawetz, 2004) also affect women's decision or refusal to participate in labour force. Furthermore, women's non-participation in labour force are necessary to also ascertain the extent to which the private sector's and government's inability to make jobs available to women can be exonerated because some women might have also taken the decision to not participate in labour-regardless of the economic realities in the country- thereby obscuring and over-inflating the true magnitude of unemployment among women.

Therefore, some studies have gone beyond identifying predictors of women unemployment or inability to secure employment (Bourmpoula, Kapsos \& Pasteels, 2015), by examining factors responsible for women's labour force participation, that is, whether a woman actually works or still looking for a job (Bourmpoula, Kapsos \& Pasteels, 20I5). While some scholars have argued that non-participation of women in the labour force is not unconnected to their traditional roles and child care responsibilities (Lawanson, 2008; Bongaarts, Blanc \& McCarthy, 2018), another batch of studies examined the roles of age, education, marital status, contraceptive use and household structure in labour force participation among women (Fadayomi \& Olurinola, 20I4; Gayawan \& Adebayo, 2015). Besides, recent evidence from Ethiopia reveals that women who reported consistent use of contraceptive had a significantly higher chance of participating in the labour force (John, Tsui \& Roro, 2020). Yet, little is known about the extent to which community (sociodemographic and economic) contexts, as well as number of children living with a woman (an indicator of extent of burden of child care) and contraceptive use (at the community level), predicts women's nonparticipation in labour force.

This study is an advancement over previous studies that emphasised the impact of childcare burden and home-making activities on time available to women to participate in economic activities at the individual level (Jensen, 2017). This study considered the number of children living with women and the proportion not using contraceptives at the community level. This is because there is a need to look beyond factors operating at individual and household levels in researching the determinants of women's labour force participation. Existing studies on neighbourhood effects suggest that several factors within local areas can have impact sexual and reproductive health behaviour (Muchiri, Odimegwu, Banda, Ntoimo \& Adedini, 20l7; Mimiaga et al., 2015). For example, it may not be logical to conclude that women in urban areas tend to participate in the labour force than their rural counterparts because of the locational advantages of industries in urban areas. Or that educated women participate in labour force than the uneducated. It may also be methodically wrong to conclude that a woman who uses contraception is more likely to participate in labour force because of reduced fertility without considering the proportion of these covariates at the community level.

This is because two individuals with similar socioeconomic characteristics and who stay in different environments tend to exhibit different behaviour. Women in rural areas may engage more in labour force because there are interventions for women in rural areas. One could also conjecture that the proportion of women in the community who use contraceptives- a departure from previous studies that focused on individual women use of contraceptive- explains labour force participation 
better. However, there is limited evidence regarding the influence of community contexts on labour force participation of women in Nigeria. This paper teased out information on community factors and labour force participation of women using nationally representative secondary data.

This study provides more empirical information that would assist policymakers (in Nigeria) in their efforts to promote women empowerment and autonomy by addressing factors inhibiting labour-force participation among women. This would help in improving women's access to decent work, boost their motivation to work (in line with the SDG eight), help reduce the level of poverty among them (in line with the Sustainable Development Goal (SDG) one) and also encourage community-based and womenempowerment interventions that include family planning and conditional cash transfer.

\section{Literature review and theoretical framework}

Several attempts have been made to provide empirical reasons why individuals participate in the labour force. The neoclassical theory of labour force participation emerged in response to this and places more emphasis on the concept of time allocation to either market or no-market activities among people. The theory acknowledges the rational decisionmaking abilities of individuals which often characterise their decision-making for time allocation. Individuals either commit to economic activities in the labour market or invest their time in leisure based on the extent benefit-cost incurable from both mutually exclusive and dichotomous choices. The benefits of participating in the labour force often result from an increase in income as a result of an increase in wage rate, the opportunity of which is leisure. On the other hand, an individual may opt for leisure as more beneficial and far less costly than work (Casale, 2003). In a nutshell, the theory places the decision-making and actual participation in the labour force within the exclusive preserve of an individual.

Nevertheless, the theory has continued to attract criticisms in the light of its oversimplified approximation of individual decision-making process and its striking failure to mirror the current realities which go beyond the two-choice model or a binary choice. Also, some critics of the theory considered its limitations from gendered perspectives. For instance, Dex $(1985: 64,78)$ refers to the theory as a perfect reflection of men's experiences and decision-making dynamics but questions its ignorance of the fact that women experiences and traditional roles of homemaking and child care activities are not akin to leisure. Moreover, for several decades, the 5173 patriarchal system often promotes labour force participation among men being the household provider while women activities are most time within the confines of the home (Lisaniler \& Bhatti, 2005). This further implies that the opportunity cost of participating in the labour force (or working) is so low among women that they often substitute homemaking for the labour force participation.

Furthermore, the argument that income almost determines time allocation has been further weakened when contextualized among women because it has been observed that the dynamics of women's decision to participate in the labour force or resort to leisure is a function of a women's characteristics among which marital status and child care burden rank so high. Mincer's (1962) study shows a significant joint effect of marital status and age of children on labour force participation among women. The study found that married women with young children were more likely to not participate in the labour force relative to their counterparts with older children. The suggests that the need to care for young children in the household is a major deterrent to participating in the labour force. Even when women eventually participate in the labour force, the need to take care of their children and other related burdens often affects their labour market performances (Becker, 1985). These findings trigger much curiosity about the role of fertility and the presence of children on labour force participation among women in developed countries (Gronau 1973, Schuktz 2009).

In the context of Nigeria, studies have been conducted to further explore and improve the level of understanding of the correlates of labour force participation among women. Many of these studies have focused on individual-level socio-demographic (such as age, marital status, education, migration and health status) economic (income) and household predictors such as the presence of children in the household and household size (Fadayomi \& Olurinola, 20I4). For example, Aromolaran (2004) identified women and male partners' education as a significant predictor of overall participation in the labour force and self-employment among married women in Nigeria. Also, the influence of the presence of an elderly female in the household on women's labour force participation has been established (Aminu, 2010), while another study focused on the influence of household structure alongside other individuallevel factors (Fadayomi \& Olurinola, 20I4, Gayawan \& Adebayo, 2015).

Based on these studies, the effects of individual and household-level factors on labour force participation are well established, yet the studies http://aps.journals.ac.za 
create the need to interrogate further the influence of community-level considering the nestedness of individuals within households which in turn are nested within communities. This knowledge-gap necessitated the adaption of the socio-ecological theory to examine the neighbourhood factors influencing labour force participation of women. According to the theory, socio-ecological factors are structurally multilevel or hierarchical. These hierarchical factors extend from the individual and household level to much larger levels such as the organizational, community and public policy levels and also interplay to determine human development as well as human behaviour (Bronfenbrenner, 1977).

In the light of this, this study hypothesised that, apart from the individual-level and traditional sociodemographic and economic variables, communityfactors are potential determinants of nonparticipation in the labour force among women of reproductive age in Nigeria. Therefore, this study considered the influence of the following communitylevel variables: type of place of residence, the region of residence, community-level poverty, community level of lack of education, community number of children living with women and community non-use of contraceptive.

Besides, this study further extended the frontiers of knowledge on the role of the presence of children in the household and fertility behaviour on labour force participation among women by examining the extent to which the number of children living a woman determines her non-participation in labour in line with past and recent studies that examined the relationship between fertility and unemployment among women in Nigeria and other countries (Olowa and Adeoti, 2014; Bloom et al., 2009; Obiyan et al., 2017), as well as and the link between the presence of children (and child care burden) and women's participation in the labour force (Schaner \& Das, 2016). Furthermore, the inclusion of contraceptive use draws strength from the WHO's (2018) assertion that, lack of family planning is associated with economic incapacitation among women.

To further this discourse, we put forward another hypothesis regarding the possible influence neighbourhood contexts on labour force participation of women. Given that women's participation in labour force is influenced by varying cultural norms and values across the heterogeneous population in Nigeria, we hypothesized that neighbourhood contexts might influence labour force participation of women differently across diverse socio-economic and neighbourhood contexts. We raised the question: does women's labour force participation vary significantly across different socio-economic and neighbourhood contexts? We presumed that women who live in a context where there is a high prevalence of contraception and childcare support are more likely to participate in the labour force. To test this hypothesis, we analysed nationally representative secondary data.

\section{Data and methods}

This study utilised data from the 2016-20I7 Multiple indicator Cluster Survey (MICS), a nationally representative data set that collected information from women aged 15-49 years in Nigeria. Nigeria was chosen because of the wide gender gap in labour force participation. The women recode data set was selected for the study. Women of reproductive age 18-49 years constituted the study population. This Survey- which is the fifth round since its inception in the 1990s- was conducted by the National Bureau of Statistics in conjunction with the National Primary Health Development Agency (NPHCDA) and the National Agency for Control of AIDS (NACA) with financial and technical supports from international organizations among which were the World Bank, World Health Organization (WHO) and Save One Million Lives (SOML). It provides estimates of demographic and population health indicators -at the national, regional, state and residential levels- for evaluating the achievements of the Millennium Development goals and monitoring the subsequent Sustainable Development Goals (SDGs) among other aims. In sample design, 60 Enumeration Areas (EAs) were randomly selected (systematically) from each state (i.e. the survey domain)- except Lagos and Kano States where 120 EAs were selected systematicallyfrom the National Integrated Survey of Households round 2 (NIHS2) master sample, which is, in turn, prepared based on the 2006 population census frame. A total of 2,340 EAs were systematically selected, 2,239 EAs (of these were listed and covered in the survey) and sixteen (16) households where were systematically sampled from each listed EA. A total of 34,376 women (aged 15-49 years) were successfully interviewed in the survey. To achieve the objective of the study, a weighted sample of women $(32,742)$ aged $18-49$ years who had had at least a live birth within the last five years before the survey.

\section{Variable definition and measurement}

The outcome variable non-participation of women in the labour force (current participant $(0)$ and nonparticipant (I)) was created based on TAI3C (i.e. Do you currently work in-door or outdoors?) and TAI3B (i.e. Do you currently work outside your home?). The selected individual-level socio-demographic and economic characteristics were age (WB2: $0=$ prime working-age (25-49 years), I = early working age (15-24 years), marital status (MSTATUS: not 
currently married $(0)$ and currently married $(I))$, level of education: no education (0), primary education ( $I$ ) and at least secondary education (2)) and wealth index (windex5: poorest (I), poorer (2), middle (3), richer (4) and richest (5)). The community-level variables were computed by first dropping clusters with less than 10 observations, then aggregating the proportion of women with the characteristics of interest (for instance, proportion of women in the poor wealth index) in each cluster (WMI) community and grouping the results. Apart from place of residence and region, the individual-level variables were aggregated at the level of primary sampling units to stand as community-level factors. The constructed community variables were divided into textiles and categorized as low, medium and high concentrations. Thus, community characteristics were: community with the high number of children living (with women) in the household (low number of children (I), medium (2) and high (3), community non-use of contraceptive (low non-use (I), medium (2) and high (3)), community poverty (low poverty ( 1 ), medium (2) and high (3)), community noneducation (low level of non-education (I), medium (2), high (3)). Other community-level variables like community rurality ( $\mathrm{HH} 6$ : urban (0), and rural (I)) and community region (zone: south (0) and north (I) were not aggregated.

Other control variables were contraceptive use (CPI and CP2: using (0) and not using (I)) and number of children living with a woman. The latter was defined as never given birth (0), the group with no children living with them (I), and those with children living with them (2) on based responses to variable CMI (i.e. ever given birth?), CM5A (sons living with you) and CM5B (daughters living with you).

\section{Statistical analysis and modelling}

Three levels of analysis, including univariate, bivariate and multivariate, were employed in this study. At the univariate level of analysis, frequency and percentage distributions of all the variables were presented. At the bivariate level, cross-tabulation and Chi-square statistical test were used to examine the relationship between each of the contextual variables and the outcome variable. At the multivariate level, the multilevel binary logistic regression model was used to tease out the effects of community contexts on non-participation of women in the labour force. This was because of the dichotomous nature of the outcome variable. Four models were fitted to achieve the study's objective. The multilevel logistic regression was considered appropriate owing to the clustered structure of the data and the stratified5175 cluster sampling technique adopted in the MICS which violates the independence assumption of regression analysis. Moreover, the use of multilevel modelling has become highly relevant and useful in studying social and behavioural outcomes in the social sciences (Steenbergen \& Bradford, 2002; Kelleher \& Wolak 2007; Hakhverdian \& Mayne, 20I2; McLaren, 2012; Adewole, Adedini, \& Bisiriyu, 2018).

Model I contains only number of children living with the woman and current use of contraceptive. Model 2 contains age, marital status, level of education and wealth index and Model 3 contains only the community-level factors while Model 4 (full model) incorporated all the variables (i.e. explanatory and contextual variables). Besides, multilevel binary logistic regression analysis was employed to account for the clustering of observation, binary nature of outcome variable and the assumption of homogeneity of residual variance in the standard regression model is often not valid owing to the hierarchical structure of the clustered data. Thus, this study employed multilevel modelling to account for residual variance. In the multilevel model, the probability of nonparticipation of women in labour force was considered as the odds. The odds were modelled using the mathematical equations advanced below:

The multilevel logistic regression model employed is mathematically expressed as

$Y_{i j}=\beta_{0}+\beta_{1} X_{1}+\beta_{2} X_{2}+\ldots+u_{j}+e_{i}$

Where

$Y_{i j}=\log$-odds of non-participation in labour force

$\beta_{0}=$ Intercept (Average log-odds of nonparticipation in labour force)

$\beta_{1}, \beta_{2}=$ Coefficients for individual and community-level variables

$X_{k i j}=$ Individual-level variables (age, marital status, level of education and wealth index) for the woman $i$ in community $j$

$u_{j}=$ Community-level variables (place of residence, region, community poverty etc.)

$e_{i}=$ Error terms for the individual-level

The Intra Class Correlation (ICC), estimated as $\frac{\sigma_{u}}{3.29+\sigma_{u}} \quad$ (Twisk, 2006) (where $\sigma_{u}$ is the variance of the individual -

level error term ) was used to examine the correlation of non-participation in the labour force in the community or the extent to which women in the community are similar in terms of non-participation in the labour force.

The data were managed and analyzed (using appropriate sample weights) with the Stata analytical package (version I4).

Ethical considerations

http://aps.journals.ac.za 
The study used a secondary dataset of 2016-2017 Multiple indicator Cluster Survey (MICS) conducted by the National Bureau of Statistics in conjunction with National Primary Health Development Agency (NPHCDA) and National Agency for Control of Aids (NACA) in Nigeria among women aged 15-49 years. The use of the survey data was obtained with permission from the site: mics.unicef.org/surveys. Hence this study is standing on the existing ethical consideration obtained by the National Bureau of Statistics, National Primary Health Development Agency (NPHCDA) and National Agency for Control of AIDS (NACA).

\section{Results}

\section{Descriptive results}

Table I shows that more than half $(73 \%)$ of all the women were not participating in labour force. Majority $(80 \%)$ of the women belonged in the prime working age. More than half $(59 \%)$ of the women had at least primary education, less than half (42\%) were at least richer, more than half (64\%) were rural residents and less than three-quarters were in the northern region. In terms of community-level variables, more than a fifth (22\%) of all women resided in communities with a high proportion poor women (of reproductive age); more than a quarter $(36 \%)$ of all the women resided in communities with high proportion of uneducated women (of reproductive age); more than a quarter $(34 \%)$ of all women resided in communities where high proportion of women (of reproductive age) had high number of children living with them; more than a quarter $(35 \%)$ of all women resided in communities where there was high proportion of non-use of contraceptive among women of reproductive age. More than half $(57 \%)$ of all women lived in communities with high proportion women (of reproductive age) having at least two children living with them while majority of all women lived in communities where high proportion of women (of reproductive age) (88\%) didn't use contraceptive.

Table I: Distribution of women (of reproductive age) by non-participation in labour force and individual and community-level characteristics

Variables n (\%)

Non-participation in Labour force

Non-participant

$23,792(72.9)$

Participant

$8,843(27.1)$

Age

Early working age

$6,579(20.1)$

Prime working age

$26,163(79.9)$

Marital Status

Unmarried

$9,389(28.7)$

Married

$23,28 \mid(7 \mid .3)$

Level of education

No education

$7,676(23.4)$

Primary

$4,663(14.3)$

At least secondary

$14,776(45.1)$

Non-formal education

$5,627(\mid 7.2)$

Wealth Index

Poorest

$6,067(18.5)$

Poorer

$6,297(19.2)$

Middle

$6,339(19.4)$

Richer

$6,522(19.9)$

Richest

$7,517(23.0)$

Community-level variables

Place of residence

Urban

II,690 (35.7)

Rural

$21,052(64.3)$

Region of residence 
North

South

Community poverty: $\%$ of women in

poor wealth quintile

Low

Medium

High

$10,92 \mid(22.4)$

Community-level of no education: \% of women with no education

Low

Medium

High

II,767 (35.9)

Community number of children living with women: $\%$ of women with at least two children living with them

Low

Medium

$9,976(30.5)$

High

Community non-use of contraceptive: \% of women not using contraceptive

Low

Medium

High

Number of children living with a woman

None

One

Two

More than two

Current use of contraceptive

Using

Not using

Bivariate analysis results

Percentage distribution of non-participation in the labour force by individual and community-level characteristics was presented in Table 2. There was a significant association between individual and community variables and non-participation in the labour force (at $\mathrm{p}<0.05)$. Slightly more than threequarters $(76 \%)$ of non-participants in the labour force were women in prime working-age. More than half of non-participants were married (7/\%), had at least secondary school education $(60 \%)$ respectively, while more than a half $(44 \%)$ were poor. More than half of non-participants were rural residents $(68 \%)$ while most non-participants $(81 \%)$ resided in northern communities. Concerning community poverty, more than a quarter of non-participants $(40 \%)$ lived in communities with high number of poor women of reproductive age. More than a twofifths $(42 \%)$ of non-participants in labour force resided in communities with a high proportion of uneducated women (of reproductive age); more than a quarter resided in communities with a high number of children living with the women (of reproductive age) (38\%) and more than two-fifths resided in communities with a high proportion of women (of reproductive age) who didn't use contraceptive (4I\%).

Furthermore, the number of children living with a woman and contraceptive use were, respectively, significantly associated with non-participation in the labour force (at $p<0.05)$. More than half $(55 \%)$ of non-participants in the labour force had at least two children living with them, while the majority was not using contraceptive (92\%). 
Table 2: Relationship between contextual variables, other control variables and non-participation in the labour force

Individual-level variables

\section{Age}

Early working age

Prime working age

Marital Status

Unmarried

Married

Level of education

No education

Primary

At least secondary

Non-formal education

Wealth Index

Poorest

Poorer

Middle

Richer

Richest

Community-level variables

Place of residence

Urban

Rural

Region of residence

North

South

Community poverty: $\%$ of women in poor wealth quintile

Low (RC)

Medium

High

Community-level of no education: \% of women with no education

Low (RC)

Medium

High

Community number of children living with women: \%

of women with at least two children living with them

Low (RC)

Medium

High

Community non-use of contraceptive: $\%$ of women not using contraceptive

Low (RC)

Medium

High

Number of children living with a woman

None

One

Two

More than two

Current use of contraceptive

Using

Not using
Non-participation in labour force

442.0*

$5,691(23.9)$

$|8,10|(76.1)$

$6,943(29.2)$

$16,803(70.8)$

$6,375(26.8)$

$3,133(13.2)$

$9,085(38.2)$

$5,198(21.8)$

$5,329(22.4)$

$5,188(21.8)$

$4,825(20.3)$

$4,357(18.3)$

$4,093(17.2)$

4.9*

$238.6 *$

$148.7^{*}$

$74.2^{*}$

$7,486(31.5)$

$16,306(68.5)$

$19,403(81.5)$

II79.9*

$4,389(18.5)$

6,635 (27.9)

$7,711(32.4)$

$9,447(39.7)$

$5,406(22.7)$

$8,487(35.7)$

$9,898(4 I .6)$

II3.|*

$7,655(32.2)$

$7,187(30.2)$

$8,950(37.6)$

$5,520(23.2)$

$8,549(35.9)$

$9,722(40.9)$

$7,134(30.8)$

$3,189(13.8)$

$3,133(13.5)$

$9,697(41.9)$

$1,933(08.2)$

21,781 (91.8)
136.3*

$30.7^{*}$

$161.7^{*}$

$28.9 *$

$420.1 *$ 
*significant at $p<0.05$

\section{Multivariable analysis results}

Results of multilevel binary logistic regression analysis were presented in Table 3. Model I shows a significant relationship between non-participation in labour force and children living arrangement on the one hand, and contraceptive use, on the other hand. Compared to women with no children living with them, women having one, two and more than two children living with them were respectively $51 \%$ (OR $=0.49 ; \mathrm{Cl}=0.44-0.55), 62 \%(\mathrm{OR}=0.38 ; \mathrm{Cl}=$ $0.34-0.42)$ and $62 \%(\mathrm{OR}=0.38 ; \mathrm{Cl}=0.34-0.4 \mathrm{I})$ less likely to not participate in labour force. Women that are not currently practising contraception were approximately twice as likely $(\mathrm{OR}=1.72 ; \mathrm{Cl}=1.56$ I.89) to not participate in the labour force compared with those using contraception.

Model 2 shows the relationship between the individual and community characteristics and nonparticipation of women in the labour force. The results showed a statistically significant relationship between age, marital status, level of education, wealth index and non-participation in the labour force. Specifically, being in a prime working-age group- relative to early working age- was associated with $72 \%(\mathrm{OR}=0.28 ; \mathrm{Cl}=0.28-0.3 \mathrm{I})$ reduced likelihood of non-participation in labour force. Compared to the single ones, married women were I3\% (OR $=0.87$; $\mathrm{Cl} 0.79-0.96)$ less likely not to participate in the labour force. The likelihood of not participating in the labour force among women with no education and women with non-formal education (compared to those who had at least a secondary education) increased by $77 \%(\mathrm{OR}=1.77 ; \mathrm{Cl}=$ I.55-2.03) and four folds $(\mathrm{OR}=3.84 ; \mathrm{Cl}=3.06$ 4.83) respectively while those who with primary education had increased an odds of $4 \%$ nonparticipation in the labour force $(O R=1.04 ; \mathrm{Cl}=$ 0.94-I.14). There was a dose-response relationship between wealth index and non-participation in labour force such that women who were in the poorest, poorer, middle, richer and richest quintiles were respectively three times $(\mathrm{OR}=3.00 ; \mathrm{Cl}=2.48$ 3.64), twice (OR $=2.32 ; \mathrm{Cl}=1.98-2.73)$, twice (OR $=1.63 ; \mathrm{Cl}=1.42-1.87)$, and $28 \%(\mathrm{OR}=1.3 \mathrm{I} ; \mathrm{Cl}=$ I. 19-I.46) more likely to not participate in the labour force.

Model 3 examines the effect of contextual factors on non-participation in the labour force. The results show that all contextual variables place of residence, community non-education, community number of living children were significantly related to nonparticipation in labour force. Rural dwellers were $7 \%$ more likely $(\mathrm{OR}=1.07 ; \mathrm{Cl}=0.94-\mathrm{I} .24)$ to not 5179 participate in the labour force relative to the urban dwellers. Women residing in communities in the northern region of Nigeria were about six times more likely (OR $=5.88 ; \mathrm{Cl}=5.08-6.82)$ to not participate in the labour force compared to their counterparts in the south. Compared to living in wealthy communities, those residing in a moderately poor and highly poor communities are $5 \%$ (OR = I.05; $\mathrm{Cl}=0.90-\mathrm{I} .22)$ and $86 \%(\mathrm{OR}=1.86 ; \mathrm{Cl}=$ I.45-2.38) respectively were more likely to not participate in labour force. While women who resided in communities characterised by a medium level of no education were $2 \%(O R=1.02 ; \mathrm{Cl}=$ 0.87-I.19) more likely to not participate in the labour force (relative to those living in communities with far less education), women living in the a-highlyuneducated-members-dominated community were I7\% (OR $=0.83 ; \mathrm{Cl}=0.65-\mathrm{I} .06)$ less likely to not participate in the labour force. Women dwelling in communities where most women had more than two children living with them were $3 \%(\mathrm{OR}=1.03 ; \mathrm{Cl}=$ 0.87-I.24) more likely not to participate in the labour force compared with communities with a fewer number of children in the household. Contrarily, women residing in a community where women had an average number of children in their household were $6 \%(\mathrm{OR}=0.94 ; \mathrm{Cl}=0.8 \mathrm{I}-\mathrm{I} . \mathrm{I})$ ) less likely to not participate in the labour force. In a community with a high non-use of contraceptive, women were three times as likely $(\mathrm{OR}=3.08 ; \mathrm{Cl}=2.57-3.69)$ not to participate in the labour force compared with communities with a high proportion of contraceptive users. Also, in communities where there was a medium proportion of contraception non-users, women were $77 \%(\mathrm{OR}=1.77 ; \mathrm{Cl}=1.52-2.07)$ more likely not to participate in the labour force.

The full model encompasses all the variables under study to examine their marginal effects on nonparticipation in the labour force. Based on the overall results, number of children living with a woman, current use of contraceptive, as well as individuallevel socio-demographic and economic variables (such age, level of education and wealth index) and contextual factors (such as community poverty, community number of children in household, community level non-use of contraceptive and region of residence) had statistically significant relationship with non-participation in the labour force. Compared to women with no children living with them, women having one, two and more than two children living with them were respectively $25 \%$ (OR $=0.75 ; \mathrm{Cl}=0.65-0.87), 31 \%(\mathrm{OR}=0.69 ; \mathrm{Cl}=$ $0.60-0.80)$ and $20 \%(\mathrm{OR}=0.80 ; \mathrm{Cl}=0.69-0.92)$ less likely to not participate in labour force. Women 
who were not currently practising contraception were $46 \%$ more likely $(\mathrm{OR}=1.46 ; \mathrm{Cl}=1.33-\mathrm{I} .6 \mathrm{I})$ to not participate in the labour force compared to the reference category (i.e. those practising).

In terms of age, being in a prime working-age grouprelative to early working age was associated with a $66 \%(\mathrm{OR}=0.34 ; \mathrm{Cl}=0.30-0.38)$ reduction in the likelihood of not to participate in the labour among women. The likelihood of not participating in the labour force among women with no education and women with non-formal education (compared to those who had at least a secondary education) increased by $35 \%(\mathrm{OR}=1.35 ; \mathrm{Cl}=1.17-\mathrm{I} .55)$ and two folds (OR $=2.34 ; \mathrm{Cl}=1.87-2.93)$ respectively while the reverse was the case among those who had primary education with $1 \%(\mathrm{OR}=0.99 ; \mathrm{Cl}=0.84$ I.03) reduction in the likelihood of non-participation in the labour force. Women who were in the poorest and poorer quintiles were $32 \%(\mathrm{OR}=1.32 ; \mathrm{Cl}=$ $\mathrm{I} .05-\mathrm{I} .65)$ and $31 \%(\mathrm{OR}=\mathrm{I} .3 \mathrm{I} ; \mathrm{Cl}=\mathrm{I} .09-\mathrm{I} .58)$ more likely to not participate in the labour force compared with the women in the richest quintile. Women in the middle and richer quintiles were respectively $24 \%(O R=1.24 ; \mathrm{Cl}=1.06-1.44)$ and $15 \%(\mathrm{OR}=1.15 ; \mathrm{Cl}=1.03-1.29)$ more likely to not participate in the labour force.

Women residing in communities in the northern region of Nigeria were five times more likely $(O R=$ $5.42 ; \mathrm{Cl}=4.66-6.30)$ to not participate in the labour force compared to their counterparts in the south. Compared to those living in wealthy communities, women residing in a moderately poor were $5 \%$ (OR $=0.95 ; \mathrm{Cl}=0.82-\mathrm{I} . \mathrm{II}$ ) less likely to not participate in labour force while women in highly poor communities were $38 \%(\mathrm{OR}=1.38 ; \mathrm{Cl}=1.05$ -
I.8I) more likely to not participate in the labour force. Women dwelling in communities where most women had more than two children living with them were $19 \%(O R=1.19 ; \mathrm{Cl}=1.00-1.43)$ more likely to not participate in the labour force compared to communities with a fewer number of children in the household. On the contrary, women residing in a community where women had an average number of children in their household were $5 \%(O R=1.05 ; \mathrm{Cl}$ $=0.89-1.23$ ) more likely not to participate in the labour force. In a community with a high non-use of contraceptive, women were twice as likely $(O R=$ 2.49; $\mathrm{Cl}=2.07-3.0 \mathrm{I})$ to not participate in the labour force compared with communities with a high proportion of contraceptive users. Also, in communities where there was a medium proportion of non-users of contraception, women were $59 \%$ $(\mathrm{OR}=1.59 ; \mathrm{Cl}=1.36-\mathrm{I} .86)$ more likely to not participate in the labour force.

\section{Random effects}

Results from the null model (Model 0) which was fitted to decompose the total variance into its individual and community-level components showed a significant variance across the community, thereby justifying the use of multi-level modelling. The ICC calculated form the null model was $51 \%$, which means that a little above half of the total variation in non-participation in the labour force was explained by the community in which women lived. Although the ICC decreased from $52 \%$ to $33 \%$ from model I to the full model, the ICC remained statistically significant all through. 
African Population Studies Vol.34, No.2, Sept./Oct. 2020

Table 3: Relationship between contextual characteristics, contraceptive use, number of children living with woman and non-participation in the labour force

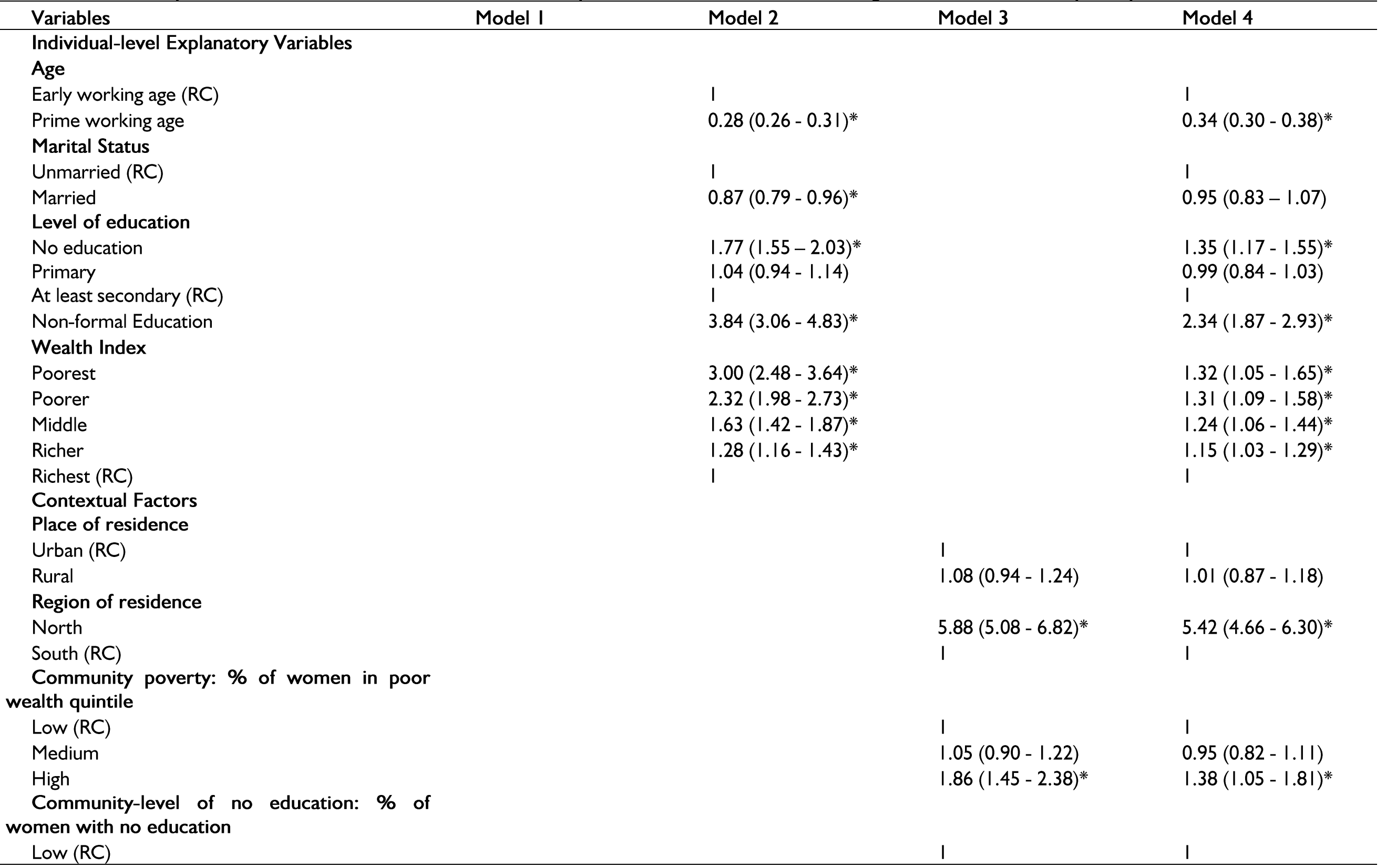


African Population Studies Vol.34, No.2, Sept./Oct. 2020

\begin{tabular}{|c|c|c|c|c|}
\hline Medium & & & $1.02(0.87-1.19)$ & $1.00(0.85-1.17)$ \\
\hline \multicolumn{5}{|c|}{$\begin{array}{l}\text { Community number of children living with } \\
\text { women: \% of women with at least two children } \\
\text { living with them }\end{array}$} \\
\hline Low $(\mathrm{RC})$ & & & I & I \\
\hline Medium & & & $0.94(0.81-1.10)$ & $1.05(0.89-1.23)$ \\
\hline High & & & $1.03(0.87-1.24)$ & $1.19(1.00-1.43)^{*}$ \\
\hline \multicolumn{5}{|c|}{$\begin{array}{l}\text { Community non-use of contraceptive: } \% \text { of } \\
\text { women not using contraceptive }\end{array}$} \\
\hline Low (RC) & & & I & I \\
\hline Medium & & & $\mathrm{I} .77(\mathrm{I} .52-2.07)^{*}$ & $1.59(\mathrm{I} .36-\mathrm{I} .86)^{*}$ \\
\hline High & & & $3.08(2.57-3.69)^{*}$ & $2.49(2.07-3.01)^{*}$ \\
\hline \multicolumn{5}{|c|}{ Number of children living with a woman } \\
\hline None (RC) & I & & & I \\
\hline One & $0.49(0.44-0.55)^{*}$ & & & $0.75(0.65-0.87)^{*}$ \\
\hline Two & $0.38(0.34-0.42)^{*}$ & & & $0.69(0.60-0.80)^{*}$ \\
\hline $\begin{array}{l}\text { More than two } \\
\text { Current use of contraceptive }\end{array}$ & $0.38(0.34-0.4 I)^{*}$ & & & $0.80(0.69-0.92)^{*}$ \\
\hline Using (RC) & 1 & & & I \\
\hline $\begin{array}{l}\text { Not using } \\
\text { Random effects }\end{array}$ & $\mathrm{I} .72(\mathrm{I} .56-\mathrm{I} .89)^{*}$ & & & $1.46(1.33-1.6 \mathrm{I})^{*}$ \\
\hline $\begin{array}{l}\text { Variance (SE) } \\
\mathrm{ICC}(\mathrm{Cl})\end{array}$ & $3.63(0.14)$ & $2.21(0.11)$ & $1.64(0.07)$ & $1.61(0.08)$ \\
\hline Null model $=0.5 \mathrm{I}(0.48-0.53)$ & $0.52(0.49-0.54)$ & $0.4 \mathrm{I}(0.38-0.43)$ & $0.33(0.31-0.35)$ & $0.32(0.30-0.35)$ \\
\hline $\begin{array}{l}\text { Fitness of Model } \\
F(d f l, d f 2)\end{array}$ & $167.09(4,1885)^{*}$ & | $32.05(9, \mid 880)^{*}$ & $193.91(10,1879)^{*}$ & $106.93(23,1866)^{*}$ \\
\hline
\end{tabular}

RC - Reference Category; *Significant at $\mathrm{p}<0.05$. 


\section{Discussion}

The study examined the relationship between contextual characteristics, contraceptive use, children living arrangement and non-participation of women in labour force in Nigeria. This study revealed some salient findings. Majority (73\%) of all the interviewed women were non-participants in the labour force. This is higher than the $50 \%$ women labour force non-participation rate in 2011 (Adeyem, Odusina, and Akintoye, 2016) and the estimates of $51 \%$ in 2014 (Fadayomi \& Olurinola, 20|4), although cited reports were not strictly among women of reproductive age. Also, non-participation in the labour force was more pronounced among women in prime working age, married women, women who had at least a secondary education, poor women, those with at least two children living with them, and women not practising contraception. Also, nonparticipation in the labour force was more prevalent in rural communities, northern communities, poor communities, highly uneducated communities, community with the high number of children living with the women in the household and communities where non-use of contraceptive was high among the women.

We found out that non-use of contraceptive increases the odds of non-participation in the labour force but, having a higher number of children living with a woman does otherwise. The role of the number of children living with a woman aligns with other studies in which a link exists between fertility and employment (Olowa \& Adeoti, 20l4; Bloom et al., 2009). Previous studies also shed light on why reduced or non-participation in the labour force among women is due to their exposure to the burden of childcare (Chevalier \& Viitanen, 2002; Schaner \& Das, 2016). However, recent evidence supports our finding that female employment is associated with increased fertility especially among married women in Nigeria (Obiyan et al., 2017). The plausible explanation is that women with many children have child care support and/or may be encouraged to work and take financial responsibilities to support the household. Concerning contraceptive use, the study conducted by John, Tsui, and Roro (2020) in Ethiopia among women living in a periurban concluded that the quality of contraceptive use directly or indirectly increases their labour force participation. Women who are contraceptive user have a higher chance of participating in the labour force than those who are not using contraceptives and are in the same demographic and socioeconomic group. The relationship between non-use of contraceptive and non-participation in the labour force, based on this study supports the proposition 5183 that lack of family planning economically disempowers and limits women (WHO, 2018).

Concerning contextual characteristics, individuallevel socio-demographic and economic characteristics (such as age, level of education and wealth index) were associated with non-participation in the labour force. Specifically, women in the prime working-age were less likely to be non-participants in the labour force. This is consistent with Diraditsile and colleague's (2017) study in Botswana that reveals a high level of unemployment among young women. However, the study population age classification overlaps women of prime working age and women not in the prime working-age compared with our study. The Botswanan study focused on women aged 20-35 years which includes women of prime working age.

Also, women with no formal education or no form of education were more likely not to be participating in the labour force. This further lends credence to the importance of education in improving participation in the labour force among women (Khanie, 2019, Bbaale \& Mpuga, 201 I, Nwokoye et al., 2017, Sadiq et al., 2017, Verick, 2014). Nevertheless, it has been observed that the influence of education weakens when women get married, thus increasing their inability to secure employment (Dieterich, Huang \& Thomas, 2016) while another study in Cameroon has shown that increased exposure to education among women increases their participation in labour force regardless of their fertility (Yeyouomo, 2016).

Residing in rural areas and in the northern region of the country significantly explained the variation in non-participation in the labour force (among women) and further emphasized the extent of the influence of urbanity and geographic characteristics (Fadayomi \& Olurinola, 20I4, Hussain et al., 20I I).

Although poor women are most likely to be unemployed, findings also revealed that wealthier women are also likely not to participate in the labour force. The latter finding may be explained using the model of negative income effect, which suggests that achieving a target income could leave more room for leisure rather than seeking employment or working. Hence, wealthy women may be more likely not to participate in the labour force or postpone participation. It is also possible that the interviewed wealthy women were self-employed and less likely to have personally worked considering the framing of the question on working status in the survey. On the other hand, poor women are economically incapacitated and less likely to start their businesses and work for themselves. 
Regarding community characteristics, most of the women residing in rural areas or the northern region of the country were at greater risk of not participating in the labour force. This corroborates the report by Mayah and colleagues (20I7), which shows that majority of women residing in the rural area and those in the northern part of the country are economically disadvantaged. Also, majority of women in a poor community and those in the lesseducated community were prone to being out of the labour force. This also echoes findings from past studies that established that poverty rate and per capita income had a significant influence on labour force participation in Northern Nigeria (Sadiq et al., 2017, Verick, 2014).

Further, non-participation was associated with communities in which women had more children living with them, and communities where there were more non-users of contraceptive. Our findings provide support to the argument that labour force participation of women has fertility-reducing effects. Women who live in a community where contraceptives are barely used tend to have many children to care for and in turn limits participation in labour force. Also, women in a community with high fertility have many children living with them and this, in turn, has limiting effects on labour force participation. These findings can be situated within the socio-ecological theory with the main thesis that community-level socio-economic factors affect human behaviour (Bronfenbrenner, 1977). These findings corroborate past and recent studies on social and behavioural implications of differentials in contextual characteristics and factors (Steenbergen \& Bradford, 2002; Kelleher \& Wolak 2007; Hakhverdian \& Mayne, 2012; McLaren, 2012; Adewole, Adedini, \& Bisiriyu, 2018). Also, the findings are consistent with the demographic transition theory which recognizes the-womenempowerment-and-autonomy-limiting power of unplanned and unregulated fertility behaviour.

\section{Conclusion}

This study concluded that majority of the women of reproductive age were not participating in labour force and that contextual factors (individual and community factors) influenced the non-participation of women (and the extent of this) in the labour force. It also reached the philosophic stance that the use of contraceptives and number of children living with a woman (in the household) affected non-participation in the labour force among women (of reproductive age) in Nigeria. Based on this, it is recommended that modern contraceptive use and keeping small family size should be encouraged among women to enable them to allocate more time to economic activities and other business opportunities while women having more children in the household should be further encouraged to maximize available employment opportunities to cater for the needs of their children. Also, women in early working age, the uneducated or those who had non-formal education as well as the poor should be targeted for more economic empowerment. To complement this effort, socio-economic development interventions that ensure access to credit facilities and promote micro, small and medium scale business must target communities in which majority of women (of childbearing age) are poor, have large family sizes (due to the high number of children in the household), do not practise contraception as well as communities in the northern region. In the long run, these community-based interventions would further reduce the poverty level in the country, enhance demographic transition and the chances of reaping demographic dividend in Nigeria.

\section{Limitations}

This study has some limitations. First, the contextual (community) variables were generated from individual-level variables. This could introduce ecological bias i.e. attributing the effect of aggregated individual-level factors to community-level factors. Second, primary sampling units served as a proxy for community. This could misclassify respondents into the wrong administrative boundaries and therefore could introduce bias. Despite these limitations, the study has some strengths. It provides empirical evidence on the influence of contextual phenomenon on women's non-participation in labour force. Also, these results could be extrapolated to the large population of women of reproductive age because this study used a nationally-representative and large survey data.

\section{References}

Adekola, P. O., Allen, A. A., Olawole-lsaac, A., Akanbi, M. A. \& Adewunmi, O. 2016. Unemployment inaps Nigeria: A Challenge of Demographic Change? International Journal of Scientific Research in Multidisciplinary Studies ISROSET, 2, I-9.

Adewole, O.G., Adedini, S.A. and Bisiriyu, L.A., 2018. Multilevel analysis of male fertility behaviour in Nigeria. African Population Studies, 32(3).

Aminu, A., 2010, May. Determinants of participation and earnings in wage employment in Nigeria. In 15th IZAWorld Bank Conference: Employment and Development, Cape Town, South Africa.

Aromolaran, A.B., 2004. Female schooling, nonmarket productivity, and labor market 
participation in Nigeria. Yale University Economic Growth Center Discussion Paper, (879).

Asoluka, N. and Okezie, I., 20I I. Unemployment and Nigerian Economic Growth. In Proceeding of the 20II International Conference on Teaching, Learning and Change. International association for teaching and learning (IATEL).

Adeyem, O.E., Odusina, K.E. and Akintoye, A.E., 2016. Religion and labour force participation in Nigeria: is there any inequality among women?. African journal of reproductive health, 20(3), pp.75-84.

Bbaale, E. and Mpuga, P., 20II. Female education, labour force participation and choice of the employment type: evidence from Uganda. International Journal of Economics and Business Modeling, 2(I), p.29.

Becker, G.S., 1985. Human capital, effort, and the sexual division of labor. Journal of labor economics, 3(I, Part 2), pp.S33-S58.

Besamusca, J., Tijdens, K., Keune, M. and Steinmetz, S., 20I5. Working women worldwide. Age effects in female labor force participation in 117 countries. World Development, 74, pp.|23-|4I.

Bloom, D.E., Canning, D., Fink, G. and Finlay, J.E., 2009. Fertility, female labor force participation, and the demographic dividend. Journal of Economic growth, I4(2), pp.79-I0I.

Bourmpoula, V., Kapsos, S. and Pasteels, J.M., 2015. ILO labour force estimates and projections: 19902050 (20I 5 edition). ILO Geneva.

Bronfenbrenner, U., 1977. Toward an experimental ecology of human development. American psychologist, 32(7), p.5/3.

Canning, D. and Schultz, T.P., 20/2. The economic consequences of reproductive health and family planning. The Lancet, 380(9837), pp.|65-I7I.

Casale, D.M., 2003. The rise in female labour force participation in South Africa: an analysis of household survey data, 1995-200I (Doctoral dissertation).

Chevalier, A., \& Viitanen, T. K. (2002). The causality between female labour force participation and the availability of childcare. Applied economics letters, 9(|4), 9|5-9|8.

Dex, S., 1985. The sexual division of work: Conceptual revolutions in the social sciences. Macmillan.

Dieterich, M.C., Huang, A. and Thomas, M.A.H., 2016. Women's opportunities and challenges in sub-Saharan African job markets. International Monetary Fund.

Diraditsile, K. and Ontetse, M.A., 20I7. Lived experiences and consequences of unemployment on women: An empirical study of unemployed young women in Mahalapye, Botswana. Journal of International Women's Studies, 18(4), pp.|31143.

Doreo, P., 2013. The Nigerian unemployment challenge. Africa Report Features.

Engelhardt, H. and Prskawetz, A., 2004. On the changing correlation between fertility and female employment over space and time. European Journal of Population/Revue européenne de Démographie, 20(I), pp.35-62.

Evans Muchiri, Clifford Odimegwu, Pamela Banda, Lorreta Ntoimo \& Sunday

Adedini (2017): Ecological correlates of multiple sexual partnerships among adolescents and young adults in urban Cape Town: a cumulative risk factor approach, African Journal of AIDS Research, DOI: 10.2989/16085906.2017.1318762

Fadayomi, T.O. and Olurinola, I., 20I4. Determinants of labour force participation in Nigeria: The influence of household structure.

Fapohunda, T.M., 20I2. Women and the informal sector in Nigeria: Implications for development. British Journal of Arts and Social Sciences, 4(I), pp.35-45.

Gayawan, E. and Adebayo, S.B., 2015. Spatial analysis of women employment status in Nigeria. CBN Journal of Applied Statistics, 6(2), pp. I-I7

Gronau, R., 1973. The effect of children on the housewife's value of time. Journal of Political Economy, 8I (2, Part 2), pp.SI68-SI99.

Hakhverdian, A. and Mayne, Q., 20I2. Institutional trust, education, and corruption: A micro-macro interactive approach. The Journal of Politics, 74(3), pp.739-750.

Hussain, M., Anwar, S. and Huang, S., 2016. Socioeconomic and demographic factors affecting labor force participation in Pakistan. Journal of sustainable development, 9(4), pp.70-79.

Jensen, P.H., 2017. Cause and effects of female labour force participation in local welfare systems.

Bongaarts, J., Blanc, A.K. and McCarthy, K.J., 2019. The links between women's employment and children at home: Variations in low-and middleincome countries by world region. Population studies, 73(2), pp.149-I63.

John, N. A., Tsui, A. O., \& Roro, M. (2020). Quality of Contraceptive Use and Women's Paid Work and Earnings in Peri-Urban Ethiopia. Feminist Economics, 26(I), 23-43.

Kelleher, C.A. and Wolak, J., 2007. Explaining public confidence in the branches of state government. Political Research Quarterly, 60(4), pp.707-72I. 
Khanie, G., 2019. Education and labor market activity of women: The case of Botswana. Journal of Labor and Society, 22(4), pp.79I-805.

Lawanson, O.I., 2008. Female labour force participation in Nigeria:'Determinants and Trends'. Department of Economics, University of Lagos, Nigeria.

Lisaniler, F.G. and Bhatti, F., 2005. Determinants of female labour force participation: a study of North Cyprus. Review of Social, Economic and Business Studies, 5(6), pp.209-226.

Mayah, E., Mariotti, C., Mere, C.E. and Odo, C.O., 2017. Inequality in Nigeria: Exploring the drivers. Oxfam International.

McLaren, L.M., 20I2. The cultural divide in Europe: Migration, multiculturalism, and political trust. World politics, pp. 199-24I.

Mimiaga, M. J., Closson, E. F., Safren, S. A., Mabude, Z., Mosery, N., Taylor,

S. W., Smit, J. A. (20I5). Inkwari: An emerging highrisk place potentiating HIV spread among young adults in a hyper-endemic South African setting. Archives of Sexual Behavior, 44(2), 307-315. https://doi.org// 0.1007/s | 0508-0| 4-0330-2

Mincer, J., 1962. Labor force participation of married women: A study of labor supply. In Aspects of labor economics (pp. 63-105). Princeton University Press.

John, N.A., Tsui, A.O. and Roro, M., 2020. Quality of Contraceptive Use and Women's Paid Work and Earnings in Peri-Urban Ethiopia. Feminist Economics, 26(I), pp.23-43.

Nwokoye, E., Dimnwobi, S.K. and Ibe, E.J., 2017. Socio-Economic Determinants of Labour Force Participation Rate in an Era of Gender Mainstreaming in Nigeria: Responses from Afikpo North, Nigeria.

Obiyan, M.O., Fagbamigbe, A.F., Adetutu, O.M. and Oyinlola, F.F., 2017. Fertility, labour force participation and poverty among married women in Nigeria. African Population Studies, 3 I (I).

Oduwole, T.A., 20I5. Youth unemployment and poverty in Nigeria. International Journal of
Sociology and Anthropology Research, I(2), pp.23-39.

Ogunlela, Y.I. and Mukhtar, A.A., 2009. Gender issues in agriculture and rural development in Nigeria: The role of women. Humanity \& social sciences Journal, 4(I), pp. 19-30.

Olowa, O.A. and Adeoti, A.I., 2014. Effect of education status of women on their labour market participation in Rural Nigeria. American Journal of Economics, 4(I), pp.72-8I.

Sadiq, A.A., Abdulhamid, A. and Muhammad, K., 2017. Logistic Regression of Factors Associated to Household Labour Participation: Maigatari LGA Jigawa State Nigeria, 2016. International Journal of Applied Science and Mathematical Theory, 3(3), pp.4I-47.

Schaner, S. and Das, S., 2016. Female labor force participation in Asia: Indonesia country study. Asian Development Bank Economics Working Paper Series, (474).

Schultz, T.P., 2009. How does family planning promote development? Evidence from a social experiment in Matlab, Bangladesh, 1977-1996. Yale University, Economic Growth Center, New Haven, Conn.

Sylvia, C. and Pedwell, C., 2008. Women, gender and the informal economy: An assessment of ILO research and suggested ways forward / SylviaChant, Carolyn Pedwell; International Labour Office. - Geneva: ILO, 2008

Steenbergen, M.R. and Jones, B.S., 2002. Modeling multilevel data structures. american Journal of political Science, pp.218-237.

Verick, S., 20I4. Female labor force participation in developing countries. IZA World of Labor.

WorldBanK 20I4. Promote gender equality and empower women by 2015 .

World Health Organization, 2018. Family planning/Contraception. Fact Sheets; 2018.

Yeyouomo, Y.B.K., 2016. The effects of fertility on the level of insertion of women in the labor market in Cameroon. African Population Studies, $30(2)$. 